\title{
BMJ Global Health Using strategic price negotiations to contain costs and expand access to medicines in China
}

\author{
Lei Si (D) , ${ }^{1,2}$ Lizheng $X{ }^{3}{ }^{3}$ Mingsheng Chen, ${ }^{4,5,6}$ Stephen Jan ${ }^{1,2}$
}

To cite: Si L, Xu L, Chen M, et al. Using strategic price negotiations to contain costs and expand access to medicines in China. BMJ Global Health 2020;5:e002256. doi:10.1136/ bmjgh-2019-002256

Received 20 December 2019 Revised 9 January 2020 Accepted 12 January 2020
Check for updates

(c) Author(s) (or their employer(s)) 2020. Re-use permitted under CC BY-NC. No commercial re-use. See rights and permissions. Published by BMJ.

${ }^{1}$ George Institute for Global Health, UNSW Sydney, Sydney, New South Wales, Australia ${ }^{2}$ UNSW Medicine, UNSW Sydney, Sydney, New South Wales, Australia

${ }^{3}$ School of Public Health, Shandong University, Ji'nan, China

${ }^{4}$ School of Health Policy and Management, Nanjing Medical University, Nanjing, China ${ }^{5}$ Creative Health Policy Research Group, Nanjing Medical University, Nanjing, China ${ }^{6}$ Center for Global Health, Nanjing Medical University, Nanjing, China

Correspondence to Dr Mingsheng Chen; cms@njmu.edu.cn
As China moves toward achievement of universal health coverage, it is critical that measures are in place to contain expenditures on medicines. Between 2001 and 2016, such expenditure rose by $664 \%{ }^{1}$ Historically, perverse provider incentives in which doctors were remunerated through commissions on markups on sales of medicines, as well as a fragmented system of regulation, have been major contributors to these cost pressures. ${ }^{23}$ While recent reforms have moved in some way to rectify these problems, ${ }^{4}$ estimates from 2016 indicate expenditure on medicines represents $36.3 \%$ of overall healthcare expenditure. ${ }^{1}$

Against this background, on 28 November 2019, China's National Healthcare Security Administration (NHSA) and the Ministry of Human Resources and Social Security released: Notice on Including Year 2019 Negotiated Medicines in 'National Basic Medical Insurance, Work-related Injury Insurance and Childbirth Insurance Medicine List (Category B)'. Lying within this seemingly anonymous report is a landmark shift in health policy in China. A key feature was a process of centralised strategic price negotiation with pharmaceutical companies underpinned by evidence from health technology assessment (HTA).

The process involved negotiations over 3 days between representatives of pharmaceutical companies and the NHSA. For each medicine, the company had two shots at bidding for a price. The medicine was rejected if both of these bids were $15 \%$ higher than the audited price provided by the NHSA. The audited price was based on independent analyses from two expert HTA panels drawn from a pool of pharmacoeconomists and health insurance auditors.

A total of 150 medicines were included in the price negotiations, including 119 new medicines and 31 previously listed medicines. The outcome was that 70 new medicines
Summary box

On 28 November 2019, China's Nation Healthcare Security Administration and the Ministry of Human Resources and Social Security released: Notice on Including Year 2019 Negotiated Medicines in 'National Basic Medical Insurance, Work-related Injury Insurance and Childbirth Insurance Medicine List (Category B)'.

- A key feature of the amendment to the list was a process of centralised strategic price negotiation with pharmaceutical companies underpinned by health technology assessment (HTA) evidence. In addition, medicines for cancers, rare diseases, chronic diseases and children's diseases were prioritised in the price negotiations.

- In China, there is a nascent HTA network housed in 48 academic centres across the country and routinely called on to conduct such studies and deliver workshops and seminars. Although it draws on much guidance from HTA institutions in high-income countries (eg, UK and Australia), it differs in its independence from government and its decentralised nature.

- It is vital for China to continue to build capacity in the field of HTA and institutionalise it into health sector decision making to expand access to healthcare at reasonable cost and thereby achieve universal health coverage.

(31\%) were listed and 27 existing medicines $(87 \%)$ were retained following these price negotiations. On average, the price of new medicines was reduced by $60.7 \%$ and that of existing medicines subjected to review reduced by $26.4 \% .^{3}$ For Category B medicines (ie, newer-generation medicines that are either patented or have recently expired patients), the patient copayment is generally set at around $50 \%$ of the listed price, although it varies among jurisdictions. After these price reductions, it is expected that such copayments will fall to below $20 \%$ of the prelisting price of the medicines. As a result of the price 


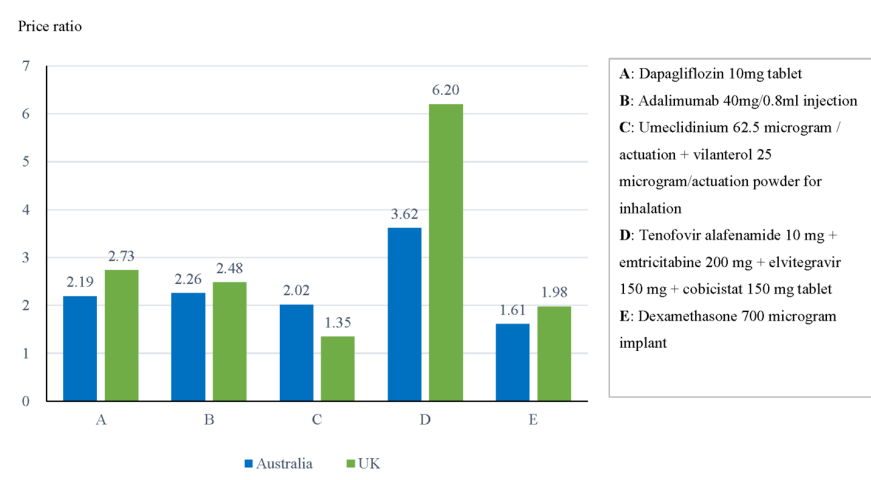

Figure 1 Price comparison of five medicines between China, Australia and the UK. ${ }^{578}$ The medicine prices are converted into US dollars ${ }^{6}$ and compared with the reference price in China.

negotiations, the price of these five selected medicines is will fall considerably.

Figure 1 illustrates the price comparison of five selected medicines with revealed price in China, Australia and the UK. For example, the price of dapagliflozin $(10 \mathrm{mg})$ per tablet is 4.36 RMB Yuan (approx. US\$0.62), ${ }^{56}$ which is cheaper than the prices in Australia (\$A2.01 or approx. US\$1.36; price ratio: 2.19) and the UK (£1.31 or approx. US\$1.69; price ratio: 2.73). ${ }^{78}$ For the selected medicines, the prices will in the UK and Australia will be between $135 \%$ and $620 \%$ of what is paid in China. ${ }^{578}$

Another feature of this round of amendments is that medicines for cancers, rare diseases, chronic diseases and children's diseases were prioritised in the price negotiations. For example, sintilimab, which is a fully human IgG4 monoclonal antibody that binds to programmed cell death receptor-1 is now publicly available to Chinese patients for the first time. Further, to tackle the burden of hepatitis $\mathrm{C}$, three new medicines have been added to the list.

This new framework for the negotiation of pharmaceutical prices represents an example of a country using its strong purchasing power to achieve lower prices in pharmaceuticals. A key element in this process is that it is not simply about driving prices to the lowest possible level, but that the negotiations are underpinned by an evidence base of the comparative value (or cost-effectiveness) of each medicine. This underlying value of each medicine, typically measured in terms of health gains, gives the purchaser (government) an idea of the price it needs to obtain in order to achieve value for money.

Such economic evidence comes from the third-party independent evaluations in the guise of HTA. In China, there is a nascent HTA network housed in 48 academic centres across the country and routinely called on to conduct such studies and deliver workshops and seminars. ${ }^{9}$ Although it draws on much guidance from HTA institutions such as the National Institute for Health and Care Excellence in the UK and the Pharmaceutical Benefits Advisory Committee in Australia, it differs in its independence from government and its decentralised nature.

The recent edition of the National Basic Medical Insurance, Work-related Injury Insurance and Childbirth Insurance Medicine List represents a landmark shift in medicines policy in China. This initiative will promote resources being allocated on the basis of value for money and lead to improvements in access to medicines for Chinese patients. In this first round of this reform, we observe reductions to price levels that are substantially lower than Australia and the UK.

This process of negotiation is underpinned by evidence generated through a formal HTA process. Building capacity in the field of HTA and institutionalising it into health sector decision making is critical for enabling countries such as China to expand access to healthcare at reasonable cost and thereby achieve universal health coverage.

Contributors All authors conceived, wrote and edited the commentary.

Funding This research is funded by the National Natural Science Foundation of China (Grant number: 71503137, 71874086) and the China Medical Board (Grant number: 19-346). LS is funded by a National Health and Medical Research Council Early Career Fellowship (Grant number GNT1139826). However, the views expressed do not necessarily reflect the policies of the grant funding body.

Competing interests None declared.

Patient consent for publication Not required.

Provenance and peer review Not commissioned; internally peer reviewed.

Data availability statement No data are available.

Open access This is an open access article distributed in accordance with the Creative Commons Attribution Non Commercial (CC BY-NC 4.0) license, which permits others to distribute, remix, adapt, build upon this work non-commercially, and license their derivative works on different terms, provided the original work is properly cited, appropriate credit is given, any changes made indicated, and the use is non-commercial. See: http://creativecommons.org/licenses/by-nc/4.0/.

\section{ORCID iD}

Lei Si http://orcid.org/0000-0002-3044-170X

\section{REFERENCES}

1 Chian Naitonal health accounts report: China Naitonal health development research center 2018.

$2 \mathrm{Hu}$ J, Mossialos E. Pharmaceutical pricing and reimbursement in China: when the whole is less than the sum of its parts. Health Policy 2016;120:519-34.

3 Liu X, Xu J, Yuan B, et al. Containing medical expenditure: lessons from reform of Beijing public hospitals. BMJ 2019;365:I2369.

4 Meng $Q$, Mills $A$, Wang $L$, et al. What can we learn from China's health system reform? BMJ 2019;395:I2349.

5 NHSA. Notice on Including Year 2019 Negotiated Medicines in "National Basic Medical Insurance, Work-related Injury Insurance and Childbirth Insurance Medicine List (Category B)": policy interpretation, 2019. Available: http://www.nhsa.gov.cn/art/2019/11/28/art_38_2056. html [Accessed 17 Dec 2019].

6 Foreign Exchange Rates - H.10. Available: https://www. federalreserve.gov/releases/h10/20191202/ [Accessed 10 Dec 2019].

7 PBS. Pharmaceutical benefits scheme (PBS). Available: http://www. pbs.gov.au/pbs/home [Accessed 11 Dec 2019].

8 BNF. BNF on formulary. Available: http://services2.ascribe.com:8080/ bnf/index [Accessed 11 Dec 2019].

9 Richards T. China to set the bar high for new health technologies, 2018. Available: https://blogs.bmj.com/bmj/2018/11/06/tessarichards-china-bar-high-new-health-technologies/ [Accessed $16 \mathrm{Dec}$ 2019]. 